\title{
Study on Competition Status and Development of Electronic Payment
}

\author{
Jiarun Li \\ College of Economics and management, Dalian University of Technology, Dalian, Liaoning, \\ 116001, China
}

\begin{abstract}
Since Taobao launched Alipay service in 2013, third-party payment platforms have begun to approach social life. In addition to the basic payment function at the beginning of development, third-party platforms led by Alipay and WeChat have diversified. With various consumption scenes as media, it has created huge economic and social benefits. At present, the third-party payment market has been basically stable, and the two giants jointly monopolize nearly $95 \%$ of the market share. WeChat and Alipay give full play to their own strengths, learn from each other's successful experience, and form a temporary balance in the game. However, there are many uncertainties in the seemingly balanced pattern. First, Apple Pay is trying to leverage the market with its userfriendliness and security advantages, with its built-in "Apple fans" and NFC near-field payment technology. Second, the central bank's upcoming launch of the digital RENMINBI also brings more uncertainty: legal digital currency may open up a new blue ocean market, enabling small and medium-sized third-party payment companies to seize the market and dilute the current monopoly. Based on the characteristics of WeChat, Alipay, Apple Pay and the digital currency of the Central Bank, this paper makes a comparative analysis of their competitive advantages, so as to predict the future trend of the third-party payment market and provide feasible suggestions for the transformation of WeChat and Alipay.
\end{abstract}

Keywords: Third Party Payment; Apple Pay; Digital RMB; Opportunities and Improvements.

\section{Analysis of the Causes of Failure of Apple Pay}

\subsection{Disadvantages of Market Size}

According to Davidor's Law, the first-generation product that enters the market automatically gets 50\% market share. On October 18, 2003, Taobao launched Alipay service for the first time and became the world's largest mobile payment provider in the second quarter of 2014. On August 5, 2013, Tenpay cooperated with WeChat to launch WeChat Pay, and WeChat Pay was officially launched. On February 18, 2016, When Alipay and WeChat Tenpay occupied $92 \%$ of the total market share (as shown in Table 1) and basically completed the comprehensive coverage of domestic merchants, Apple Pay just entered the Chinese market.

Table 1. Market share of China's third-party mobile payment transaction size in 2016 Q4 (a)

\begin{tabular}{|c|c|}
\hline Pay enterprise & Transaction Size (100 million Yuan) \\
\hline Openblock & 4963.4 \\
\hline Linkage advantage & 1694.0 \\
\hline All payment & 1647.4 \\
\hline Jingdong wallet & 1621.5 \\
\hline Quick & 1315.3 \\
\hline Yeepay pay & 1184.3 \\
\hline Suning pay & 710.6 \\
\hline
\end{tabular}




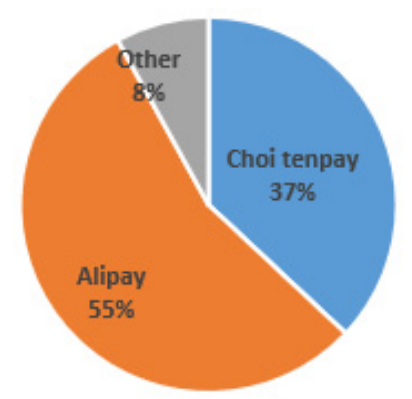

(b)

In addition to the first-mover advantage, mobile payment has the characteristics of a typical twosided market. For merchants, the number of real-name registered users of Alipay is 350 million to 400 million, and the number of users of WeChat Pay is more than 200 million. The huge user scale gives online and offline merchants a strong driving force for continuous access. For users, on the one hand, Apple Pay has high requirements on mobile hardware devices, and can only be applied to the latest Apple devices such as iPhone6 or above, iPad air2 and iwatch. Currently, there are no more than 84 million Apple Pay hardware terminals and no more than 7 million Apple Pay POS terminals in China. On the other hand, Apple Pay lacks the support of consumption scenarios such as Taobao, Tmall and WeChat business, so it cannot accumulate user data by itself. Its transaction closed loop payment service system can only exist in a limited number of bank POS terminal merchants. In a word, WeChat and Alipay have won bilateral market advantages due to their broad application scenarios and low entry threshold. Merchants and consumers show high user loyalty, and the potential market size is huge in the future, thus reducing the living space of Apple Pay and bringing nonnegligible resistance to its market expansion.

\subsection{Disadvantages of Marketing Model}

According to Metcalfe's law, user value is proportional to the square of connected users. Therefore, in order to improve the value of third-party mobile payment, the primary task is to attract user groups. In the early development of Alipay and WeChat Pay, in order to cultivate users' habits, the most commonly used marketing means is economic subsidy: reduce merchants' fee $(0.6 \%$ for ordinary merchants, as low as $0.38 \%$ ), and give users fee exemption (Alipay: exclusive red envelope; WeChat: transfer fee free). Apple Pay has a higher fee for processing payments than the two giants, putting a financial burden on merchants $(0.8 \%$ to $1 \%$ for retail and $2 \%$ for restaurants). In addition, Apple Pay, as a clearing channel for China UnionPay, already pays unionPay a certain channel fee, not to mention marketing expenses. Only commercial banks are likely to pay for economic subsidies. However, such indirect subsidies, mainly based on credit card points, are far less powerful than those offered by Alipay and WeChat.

\subsection{Hidden Dangers of Legal Compliance}

From the perspective of business compliance, Apple Pay did not obtain China's payment business license in the information announcement issued by the People's Bank of China, so its further promotion in China is also subject to a certain risk of violation. From the perspective of technical compliance, the core technology of Apple Pay application is NFC near field payment. As an emerging field, NFC has not yet formed a standardized market order, and there is no sound domestic regulations to support it. 


\section{Explore the Development Opportunities and Advantages and Disadvantages of Apple Pay}

\subsection{Analysis of Inherent Advantages of Apple Pay}

\subsubsection{Advantages of Convenience}

Scan to pay: unlock the phone - enter the app - click to pay - enter the password - confirm payment Apple Pay: The mobile phone is near the POS terminal - Touch ID

It can be seen from the process comparison that the essence of Apple Pay service is to electronize the original physical form of bank cards, thus eliminating the need to know the lock and enter the APP and greatly shortening the payment time. At the same time, this payment method is more convenient in the environment of poor network signal, which can effectively improve the user experience of the payment link.

Table 2. Comparison of basic features between Apple Pay, WeChat Pay and Alipay

\begin{tabular}{|c|c|c|}
\hline $\begin{array}{c}\text { Third-party Payment } \\
\text { Licence }\end{array}$ & $\begin{array}{c}\text { No, it provides a mobile payment } \\
\text { method based on UnionPay flash } \\
\text { payment }\end{array}$ & Yes \\
\hline Virtual account & No & $\begin{array}{c}\text { WeChat Pay, Alipay } \\
\text { pool }\end{array}$ \\
\hline $\begin{array}{c}\text { Offline payment } \\
\text { Contactless } \\
\text { withdrawal }\end{array}$ & $\begin{array}{c}\text { Support unionPay Quick Pass POS } \\
\text { terminal } \\
\text { Apple Pay on some upgraded ATMs }\end{array}$ & $\begin{array}{c}\text { Support merchants that have partnerships } \\
\text { with WeChat Pay or Alipay }\end{array}$ \\
\hline $\begin{array}{c}\text { Individual account } \\
\text { transferring }\end{array}$ & No & $\begin{array}{c}\text { No } \\
\text { There are personal transfer, AA collection } \\
\text { and red packets and other ways }\end{array}$ \\
\hline \begin{tabular}{c} 
Financial account \\
\hline
\end{tabular} & No & $\begin{array}{c}\text { Financial accounts can be opened, and funds } \\
\text { can be stored and returns can be obtained }\end{array}$ \\
\hline
\end{tabular}

\subsubsection{Security Advantages}

Table 3. Comparison of the use and security of Apple Pay, WeChat Pay and Alipay

\begin{tabular}{|c|c|c|}
\hline & Apple Pay & WeChat Pay, Alipay \\
\hline $\begin{array}{c}\text { Network } \\
\text { conditions }\end{array}$ & Phones don't need to be Connected \\
\hline $\begin{array}{c}\text { Payment method } \\
\text { offline payment) }\end{array}$ & NFC payment & Qr code scan payment \\
\hline $\begin{array}{c}\text { The password } \\
\text { input }\end{array}$ & Don't need & Need to be \\
\hline $\begin{array}{c}\text { Account } \\
\text { protection }\end{array}$ & $\begin{array}{c}\text { Account information is encrypted; The card } \\
\text { information is neither stored on the user's } \\
\text { device nor sent to the merchant }\end{array}$ & $\begin{array}{c}\text { Protect account information by password } \\
\text { protection, ID card, etc. Loss can be } \\
\text { recovered through insurance, etc }\end{array}$ \\
\hline
\end{tabular}

Apple Pay's digital transmission security technology is more stringent. First, it uses Token encryption technology to transmit sensitive customer information, instead of storing bank card information locally or on servers, avoiding the disclosure of user transaction information. Secondly, Apple Pay's NFC payment relies on real bank cards, which is a strong real-name account. However, 
qr code scanning payment on WeChat and Alipay relies on third-party payment accounts, which are weak real-name accounts. Finally, Touch ID reduces the security risks associated with entering a password.

\subsection{Weaknesses Improvement Measures}

\subsubsection{Expand User Groups}

At present, out of more than 10 million POS terminals in China, only 3 million have THE NFC payment function, and the total cost of POS terminal transformation is about 7 billion yuan. It will take time to adapt, but Apple Pay will be open to more Apple devices and even Android users. The move will not only quickly expand the scale of users, but also encourage merchants to retrofit existing POS machines.

\subsubsection{Seek Strategic Cooperation}

Apple Pay is the recipient of users' inherent capital binding. It is technically feasible to bind virtual accounts of WeChat and Alipay. Apple can first establish strategic cooperation with these two platforms, establish itself as the platform entrance of WeChat Pay and Alipay, expand its visibility in the Chinese market, and even further try to marginalize the two payment platforms.

\section{Comparative Analysis of the Advantages and Disadvantages of Alipay and WeChat Payment}

\subsection{WeChat > Alipay: Advantage Analysis based on SOLOMO Model}

\subsubsection{Advantages of Social Functions}

WeChat, as a social software with 700 million monthly active users, has a huge user base. Tencent uses its advantages in games, digital content and other aspects to offer discounts to all its products using WeChat payment, forming a payment ecosystem and greatly enhancing user stickiness.

In the follow-up upgrade, the most typical case is the WeChat red envelope introduced during the Spring Festival in 2015. This interesting and interactive payment method has rapidly expanded TenPay's user base. Subsequently, with the help of the promotion of the public account, the entity business can establish a continuous connection with users, which also provides a new way for WeChat business to sell goods. It also reduces the threshold of WeChat stores by eliminating margin and other ways to attract WeChat business users, helping traditional industries "transplant" their original business to WeChat platform, and forming a convenient business model of link + WeChat payment. Although Alipay adopts the methods of "collecting five blessings" and "Ant Forest" to make up for social defects, overall, there is still a big gap between its social functions and WeChat.

\subsubsection{Advantage of Local Payment (Local)}

With the support of GIS system, WeChat Wallet launched urban services. In cooperation with Dianping, such services as eating, drinking and playing, Didi taxi-hailing, mobile phone recharge and even charity have penetrated into consumers' lives based on their cities or life scenes.

\subsubsection{Offline Payment Advantage (Mobile)}

First of all, the service attributes of Alipay and WeChat Pay are different. For security reasons, users tend to conduct large financial management in Alipay, while demand change is mostly stored in WeChat wallet. Therefore, users are more inclined to choose WeChat Wallet with flexible payment when making small daily payments. Secondly, WeChat channel payment is more convenient for offline vendors because Alipay accounts require friends to be added to transfer money. Finally, banks have taken measures to limit third-party payments. The central bank, in a guideline on mobile payment business Development, requires individual accounts to transfer no more than 1,000 yuan in a single transaction and no more than 10,000 yuan in total annually. Compared with Alipay, WeChat focuses on small payments and is less negatively affected by policies. 


\subsection{Alipay > WeChat: Wealth Manager based on E-commerce Platform}

\subsubsection{Online Payment Advantages: High Security Guarantees Large Payment}

Alipay provides "third-party guaranteed payment" services for leading E-commerce platforms such as Taobao and Tmall, and the amount of bank cards bound by users and the amount of single transfer are much higher than WeChat. The service is based on Alipay's strong security: real-name ID information authentication, facial recognition and other strict access measures have established Alipay's position in the field of electronic payment. In contrast, WeChat's chain-based social nature has made users less likely to use WeChat Pay as an intermediary for large transfers because of security concerns such as account theft and software malfunctions.

\subsubsection{Advantages of Financial Services}

In terms of financial products, Yu 'ebao has attracted more than 300 million users with its annual profit rate far higher than bank interest rate and convenient deposit and withdrawal mechanism, thus earning the time value of a large amount of idle funds. Ant Huabei's interest-free loan service uses price lever to absorb idle funds around users. Personal score of Sesame Credit has expanded the business related to credit investigation and risk control. Compared with Alipay's wealth management products, WeChat wealth management can hardly match its functions and users' savings.

In terms of money management, Alipay supports checking bills and provides formal payment vouchers. Bills can also automatically generate charts to help users understand their spending. WeChat Wallet, on the other hand, does not have access to historical transaction information or payment details.

\section{The Future of Alipay and Wechat in the Context of Digital RMB}

Table 4. The main differences between digital RMB payment and third-party payment

\begin{tabular}{|c|c|c|}
\hline Credit system & National credit support & Credit platform support \\
\hline Privacy protection & $\begin{array}{c}\text { Controllable anonymity; Ensure } \\
\text { traceability under certain conditions }\end{array}$ & $\begin{array}{c}\text { Collect and use user data under relevant laws } \\
\text { and user authorization }\end{array}$ \\
\hline The account system & $\begin{array}{c}\text { Based on the issuance registration } \\
\text { system managed by the central bank, it } \\
\text { belongs to the account loose coupling } \\
\text { mode }\end{array}$ & $\begin{array}{c}\text { Based on accounts of third-party payment } \\
\text { institutions and reserve accounts of the central } \\
\text { bank, it belongs to the tightly coupled mode of } \\
\text { accounts }\end{array}$ \\
\hline Compensability & Infinite legal compensability & Unable to countervail \\
\hline Clearing mode & Payment on demand & Need to clear through online/unionPay \\
\hline Cost mechanism & Probably free & $\begin{array}{c}\text { Charge certain fees according to different } \\
\text { standards }\end{array}$ \\
\hline $\begin{array}{c}\text { Regulatory } \\
\text { mechanisms }\end{array}$ & Penetrating regulation is clear & $\begin{array}{c}\text { There are many regulatory links and the } \\
\text { implementation is complex }\end{array}$ \\
\hline
\end{tabular}

\subsection{Digital RMB > Alipay \& WeChat: Advantage Analysis}

\subsubsection{Credit System: National Credit Endorsement}

DECP (central bank digital currency) is endorsed by the state, supported by policies at the national level and promoted by the central bank, and has a natural credit advantage. As a central bank liability, DECP is protected by the central bank as a lender of last resort. However, for the third-party payment, it is manifested as the liabilities of commercial banks. If the third-party payment goes bankrupt, the currency will be hard to be protected. 


\subsubsection{Account System: Loosely Coupled Mode}

In loosely-coupled mode, digital wallets can not only be tied to bank cards, but can also be used independently. Therefore, DCEP supports both online and offline payments, significantly improving the user experience. However, the third-party payment adopts the tightly coupled mode, which must be bound to bank accounts and must take online transactions. Therefore, THE payment efficiency of DCEP is higher than that of third-party payment.

\subsubsection{Legal Compensation Advantage}

DCEP pass has unlimited legal compensation, that is, any transaction scenario must be unconditionally accepted. On the contrary, third-party payment has business barriers and barriers between different platforms. For example, Alipay and WeChat cannot transfer money to each other.

\subsubsection{Fee Mechanism: Non-profit}

DECP insists on the positioning of public goods and does not charge circulation fees from the issuing layer, nor does it charge service fees for digital RMB exchange and redemption from customers. However, Alipay and WeChat both adhere to the strategy of losing money in the consumer market and making profits in the merchant market, and charge higher commission fees in the merchant market (as shown in Table 5). Merchants are motivated to break away from third-party payment platforms due to the need for fee reduction.

Table 5. WeChat Pay pricing of different payment venues

\begin{tabular}{|c|c|c|c|}
\hline \multirow{2}{*}{ Type } & Pay place & Access to the income & Income ratio \\
\hline \multirow{2}{*}{ WeChat pay } & The phone APP & 300 yuan per year & Entity:0.6\% \\
\cline { 3 - 4 } & & & Technology or service: $1 \%$ \\
\hline \multirow{2}{*}{ WeChat H5 } & Web page & 300 yuan per year & Entity:0.6\% \\
\cline { 3 - 4 } & & & Technology or service: $1 \%$ \\
\hline \multirow{2}{*}{ Small program } & Small program & 300 yuan per year & Entity:0.6\% \\
\cline { 3 - 4 } & & & Technology or service: $1 \%$ \\
\hline
\end{tabular}

\subsection{Future of Alipay and WeChat}

\subsubsection{Mutual Assistance and Cooperation}

WeChat and Alipay are the core driving force for creating consumption scenes and important service providers for small and micro businesses and personal finance. DECP is bound to take thirdparty payment as a circulation carrier to reduce channel switching costs and open up profit channels. Third-party payments, which use DECP as currency, also pay the central bank. To sum up, WeChat Pay and Alipay are financial infrastructure, while DECP is a payment tool, while third-party payment and banks are still partners.

\subsubsection{Competition and Challenge}

First of all, the central bank can independently operate the digital payment wallet business, and relying on its own advantages (as described in 4.1) may cause crowding out and substitution effects on the third-party payment. Second, DECP lowers the threshold for the use of digital currency, bringing a new customer market, and this incremental market is the "blue sea" for small and mediumsized payment institutions. The monopoly of WeChat and Alipay may be weakened.

To sum up, digital payment tools have unique competitive advantages. Once they enter the thirdparty payment market, they will occupy the market share of WeChat and Alipay. At the same time, currency transformation will energize the market and may break the monopoly advantage of the two 
giants. However, platforms can also upgrade with digital currency to work with central banks to create a more transparent and secure payment environment.

\section{References}

[1] Xie Yunbo. Analysis of Apple Pay's Advantages and Disadvantages [J]. Internet World, 2016 (10): 3032.

[2] Ye Wenhui. Comparison analysis and enlightenment of ApplePay and Domestic Internet payment tools [J]. 2017 (1) Western Finance :73-76.

[3] Yue Jiaqi. A Look at three mobile payment services based on WeChat Wallet [M]. Market Watch: 103106.

[4] Xu Xin. Is there a future for Apple Pay in China? [J]. Journal of Journalism, 2016 (5).

[5] Li Jiamin. Comparative analysis of competition strategies of third-party payment industry based on SCP perspective [J]. Industrial Research, 2021 (20): 38-40.

[6] Tang Xianyi. Alipay or WeChat? Who will dominate the Internet mobile payment market? [J]. Ecommerce, 2017 (5): 64-65.

[7] Chen Yifan. Research and Analysis of third-party payment platform -- Comparative analysis of Alipay and WeChat Payment [J]. Chinese and Foreign Entrepreneurs, 2019 (13): 85-86.

[8] Liu Huijing, DING Yufeng. Comparative analysis of WeChat and Alipay two major Internet mobile payment markets [J]. Times Finance, 2018 (03): 132-136.

[9] liu zhenglong, research on the influence of digital RMB on payment market [J]. Computer and information technology, 2021(08):74,85.

[10] Zhang Rui, Digital RMB will not replace third-party payment [N]. Securities Times, 2020.5, A03.

[11] The People's Bank of China, digital RMB will not impact WeChat Pay and Alipay [N]. Times Finance, $\mathrm{XX}, \mathrm{XX}: 21-22$.

[12] Qiu Yueye, CAO Yanjun. Will the onslaught of digital yuan make the advantages of Alipay and WeChat Pay disappear? [N]. Commercial Review, 2021.11:8-11. 